Namen belegt hat. Der Name "bosniacus" ist überdies schon von Beck (Fl. v. Südbosn. VIII. (1896), p. 75) an eine Form des A. glycyophyllus $\mathrm{L}$. vergeben.

Ihr Verbreitungsbezirk, bisher auf zwei, von einander entfernte Spitzen der bosnischen und montenegrinischen Hochgebirge beschränkt, dürfte nach weiterer Erforschung der zwischenliegenden und umgebenden Gebirge noch um einige Inseln bereichert werden. Interessant bleibt es, dass diese Art innerhalb des Verbreitungsbezirkes des verwandten Astragalus vesicarius L. eingesprengt ist.

Budapest, am 7. Mai 1900.

\title{
Eine interessante Missbildung in den Blüten des Ranunculus acris L.
}

Von J. Velenovský (Prag).

Durch die gefällige Vermittlung des Herrn J. Bezděk in Politz a. d. Mettau habe ich dieser Tage eine grössere Anzahl von ganz gesund entwickelten Individuen des Ranunculus acris L. erhalten, welche eine seltene, soviel es mir bekannt ist, nirgends beschriebene Abnormität aufwiesen.

Es sitzen überall auf den Blütenästen auffallend kleine Blüten (2--3mal kleiner als bei der Normalpflanze), welche kleine, mehr keilförmige Petalen besitzen und auf dem Blütenboden nur Fruchtknoten, aber keine Antheren tragen. Diese sind ganz unansehnlich unter den Fruchtknoten als Höcker versteckt. Die Fruchtknoten gelangen regelmässig zur vollständigen Entwicklung und reifen sogar zu Früchten.

Es sind demnach weibliche Blüten, und der ganze Stock und nicht nur einzelne Individuen, sondern auch unzählige Pflanzen auf der Wiese bei Politz weiblich. Herr Bezděk schreibt, dass er auch auf anderen Standorten in der Umgebung von Politz dieselbe Erscheinung auf dem Ranunculus acris beobachtete. In der nächsten Nachbarschaft kommen aber auch ganz normale Pflanzen vor, welche zwitterige Blüten gewöhnlicher Grösse tragen.

In der Teratologie von Penzig wird ein ähnlicher Fall bei Ranunculus nicht erwähnt, nur Masters beschreibt etwas Aehnliches bei $R$. auricomus L., bei welchem die häufigsten Abnormitäten in der Blütenbildung zum Vorschein kommen.

Die Verkümmerung der Blütenkrone in den weiblich entwickelten Blüten in unserem abnormalen Falle ist anderwärts im Pflanzenreiche eine ganz normale Erscheinung. Ich erwähne z. B. die Silene-Arten aus der Verwandtschaft der Silene Otites L. oder Valeriana dioica L. Bei unseren Thymus-Arten ist es übrigens allgemein bekannt, dass einige Stöcke auf demselben Standorte rein weiblich, andere rein männlich und andere zwitterig sind, wobei die weiblichen Blüten stets kleine, verkümmerte Blumenkronen besitzen. 
Wenn wir alle diese Fälle, wo normaler oder abnormaler Weise die Corolle in den weiblich entwickelten Blüten verkümmert, vergleichen, so müssen wir zur Idee gelangen, dass die corollinisch entwickelte Blütenhülle nicht zur Function als Lockmittel für Insecten dient, weil in den bereits erwähnten Fällen, wo die Diklinie auftritt und die Bestäubung durch die Insecten noch mehr nöthig wäre, die Corolle umgekehrt verkümmert.

In meiner Arbeit „Mechy české" 1897, wo ich die Blüte der Laubmoose vom morphologischen und biologischen Standpunkte behandelte, äusserte ich ebenfalls den Zweifel. dass die gefärbte Blütenkrone der Phanerogamen als Lockmittel für die Insecten dient, wiewohl dieses Axiom in der Botanik heuzutage als allgemein geltend angenommen wird. Die sogenannte männliche Blüte der Gattung Polytrichum und anderer Laubmoose ist wohl morphologiseh mit den Blüten der Phanerogamen nieht identiseh, biologisch aber ist sie derselben Bedeutung. Wenn man z. B. die prangend rothe männliche Blüte des Polytrichum piliferum beobachtet, so kann man sich des Gedankens nicht erwehren, in derselben die echte Blüte der Phanerogamen zu sehen. In der Blüte des Polytrickum gibt es aber keine Nectarien, und die Blüte selbst wird wohl von den Insecten nicht besucht. Wozu ist hier also die Blütenhülle corollinisch entwickelt?

In der letzten Zeit wurden interessante Experimente mit künstlichen Blüten angestellt, welche beweisen, dass die Insecten bei dem Aufsuchen der Blüten durch den Geruch, nicht aber dureh die Blütenfarbe geführt werden. Diese Experimente bestätigen daher, dass die Blütenfarbe nicht für die Anlockung der Insecten dient, sondern dass sie einer anderen Deutung sein muss.

Der mechanische Zweek der Corolle ist gewiss, die Geschlechtsorgane zu schützen. Diesen Zweck kann aber dieselbe auch erreichen, ohne prächtig und auffallend schön gefärbt und ornamentalisch ausgebildet zu werden. Manche Blütenhüllen sind thatsächlich von solcher Beschaffenheit.

Ich wollte in diesen wenigen Zeilen keine Theorie auseinandersetzen, ich machte nur bei der Gelegenheit auf einige fragliche Punkte in der Deutung der Corolle der Phanerogamen aufmerksam.

\section{Acriopsis Reinw, und ihre Stellung zu den Podochilinae.}

Von Rud. Schlechter (Berlin).

Die Gattung Acriopsis wurde im Jahre 1825 von Reinwardt in der Flora Lit. v. II, p. 4 aufgestellt und mit kurzer Diagnose charakterisirt. Noch in demselben Jahre publicirte B I um e in seinen Tabellen eine Analyse der Blüte, und erläuterte die Structur derselben genauer. Seit dieser Zeit wurden von verschiedenen Autoren, wie Lindley, Wight, Ridley \& Hooker f., 